\title{
FIELD MEDICAL LASER SYSTEM
}

\author{
M. Allen, M. Gaddis, D. Garber, D. Webb \& J. Kelly (Kirtland AFB, NM) \\ M. Colvard (Schaumburg, IL)
}

\begin{abstract}
The Field Medical Laser System was developed in-house by the USAF's Phillips Laboratory. The system is a very compact device that provides the field paramedic or physician with a unique, portable, battery-operated medical capability. The laser system is able to cut like a scalpel, coagulate bleeding, and close wounds.

Introduction

EMS Physicians and battlefield medics have a continuing need to improve emergency wound procedures to reduce treatment time and trauma to the victim, thus saving lives. To meet this need, USAF's Phillips Laboratory has designed and fabricated an advanced lightweight laser system, MedPac. The MedPac consists of a completely self-contained system that is laser diode based and operates by a rechargeable battery. The laser energy is delivered to the patient by a medical fiber-optic cable, which provides a very intense power density at the tip necessary to cut and cauterize tissues.
\end{abstract}

\section{Description}

The actual system dimensions are 3" $x$ 7" $\times 9$ " and weighs eight (8) pounds, which will easily fit into a small beltpack. This system is powered by one rechargeable sealed lead acid battery. A recharging port is also provided, as is a key lock for safety and security reasons. If the system is used in a beltpack, only the optical fiber will extend from the pack. The laser light at the tip of the fiber is very intense, one kilowatt per square centimeter. Several standard disposable sterile medical tips are available that can be directly applied to the wound and are being evaluated for cutting and coagulation.

The most important electronic element in the MedPac is the high efficiency constant current laser driver. The MedPac laser driver uses the latest DC to DC converter technology combined with extremely low resistance power mosfets to provide a compact, highly efficient package which is ideally suited for battery powered field devices. Typical efficiency is greater than $82 \%$ for load currents up to 30 amps. This helps to reduce energy losses due to heat generation in the laser driver, and also extends the battery life.

An important requirement for laser driver circuits is that they accurately regulate the current flowing through the laser. The current variation for this device is typically less than $1 \%$ as the input is varied between 9 and 15 volts. Current overshoot at turn-on is less than $0.5 \%$.

DC to DC converter technology helps to reduce the current drain on the battery power source. The supply current is reduced by approximately the ratio of Vin/Vout. In the present application, which uses a 12 volt battery, the battery supplies 3.5 amps for a laser drawing 20 amps at 2.0 volts. This improves efficiency by a factor of six over a circuit using a voltage regulator to reduce the input voltage to the level required by the laser. $A 12$ volt, 4.6 amp-hour battery provides approximate 60 minutes of maximum power from the laser.

The laser driver also has a unique feature which allows it to utilize nearly $100 \%$ of the available battery energy. The internal lowdropout current regulator will keep the laser current constant until the battery voltage drops below 3.8 volts. This provides a longer useful run-time per battery charge.

The MedPac control unit is made up of three different functional parts. These are the thermal-electric (TE) cooler controller, a signal conditioning circuit for the display, and a temperature watchdog circuit.

The TE cooler circuit is made from a thermistor circuit and a switching current supply. The thermistor has a constant current flowing through it that is used to set the idle temperature of the laser. The voltage across the thermistor is fed into the switching current supply, which drives the TE cooler. The current supply has three modes of operation, on (not switching), on (switching), and off. When the laser temperature is above 17 degrees Celsius the cooler circuit is turned completely on (non-switching). It supplies 2.5 amps to the TE cooler and draws 2.5 amps. When the laser temperature reaches 15 degrees Celsius the circuit starts to switch and supplies 2.0 amps and draws 0.6 amps. As the laser reaches 14 degrees Celsius the circuit turns off. The laser temperature at system idle is between 14 and 15 degrees Celsius. The system is $90 \%$ efficient when in the switching state, and draws less than 300 micro amps in the idle state.

The front display has the ability to show either the laser temperature or laser output power. The laser power is derived from the laser current. This is only a rough estimate, because 
the power varies over temperature and the laser is set up to have a running temperature between 15 and 30 degrees Celsius. It is read from a current sensing resistor on the laser current supply board. Both the temperature and power signals are fed into a digital panel meter which is used to display them.

The temperature watchdog circuit will shut off the laser power supply when it reaches a high temperature of 30 degrees Celsius and will re-enable the laser power supply when the temperature falls below a low temperature setting of 25 degrees Celsius. The input temperature signals are derived from a thermistor.

Results

Clinical research examined the medical viability of the Field Medical Laser System. Tests were conducted with the MedPac at the University of Illinois School of Medicine in altitude chambers, and on-board aircraft from the 126th ANG, O'Hare Field, Chicago, Mlinois. Two different procedures, cutting and coagulation, were conducted with the MedPac and compared with two other medical instruments: the scalpel and the $\mathrm{CO}_{2}$ medical laser system. The tests indicated that the MedPac can function within various ground and air environments ranging from Arctic, Tropics, and pressurized flight environments.

In conjunction with the Medical School, environmental and altitude chamber tests followed a matrix that included the following scenarios:

Standard Day

Arctic (18C, $20 \%$ humidity)

Tropical (100C, $100 \%$ humidity)

Flight $(60 \mathrm{C}, 7000 \mathrm{Ft}$, pressurized)

Both lasers, $\mathrm{CO}_{2}$ and MedPac, can be varied up to nine watts of output power, but were set to operate at five watts.

\section{Standard Day}

$\begin{array}{ll}\text { Scalpel cut }(1 \mathrm{~cm}) & 2 \text { seconds } \\ \mathrm{CO}_{2} & 3 \text { seconds } \\ \text { MedPac } & 3 \text { seconds }\end{array}$

\section{Arctic Environment}

$\begin{array}{ll}\text { Scalpel cut } & 2 \text { seconds } \\ \mathrm{CO}_{2} & 4 \text { seconds } \\ \text { MedPac } & 3 \text { seconds }\end{array}$

\section{Tropical Environment}

$\begin{array}{ll}\text { Scalpel cut } & 2 \text { seconds } \\ \mathrm{CO}_{2} & 3 \text { seconds } \\ \mathrm{MedPac} & 2 \text { seconds }\end{array}$

Flight Environment

$\begin{array}{ll}\text { Scalpel cut } & 2 \text { seconds } \\ \mathrm{CO}_{2} & 3 \text { seconds } \\ \mathrm{MedPac} & 3 \text { seconds }\end{array}$

The resulting times for the incisions were not as important as the conditions of the cuts. However, the important outcome of these particular tests is that the MedPac laser provided a clean, bloodless incision.

\section{Conclusions}

The Field Medical Laser System, MedPac, provides the physician with a lightweight, portable, surgical tool that can produce immediate coagulation and closure of wounds. Furthermore, with the advent of diode laser technology, other applications are surfacing that allow for advanced battlefield trauma care. These applications include wound sterilization, bacteriology, and tissue welding. The advancements have both military and civilian purposes for stabilization of the patient. These features positively augment battlefield trauma care by disallowing loss of blood, allowing an improved view of the wound site, and maintaining controlled patient care; thereby sustaining homeostasis.

\section{Acknowledgments}

The authors wish to acknowledge one of the inventors, Captain Andy Keipert for his dedication to the Field Medical Laser System Program.

\section{References}

[1] A. Keipert, D. Garber, and M. Colvard, "Field Medical Laser System (FMLS) for USAF" Special Operations Command", Phillips Laboratory, PL-TR-94-1053, 1994. 